\title{
Effects of TMEM9 gene on cell progression in hepatocellular carcinoma by RNA interference
}

\author{
YI ZHANG $^{1}$, YAN RAN ${ }^{2}$, YAN XIONG $^{1}$, ZI-BIAO ZHONG $^{1}$, ZHENG-HUA WANG $^{1}$, \\ ${\mathrm{XIAO}-\mathrm{LI} \mathrm{FAN}^{1} \text { and QI-FA YE }}^{1,3}$
}

\begin{abstract}
${ }^{1}$ Zhongnan Hospital of Wuhan University, Institute of Hepatobiliary Diseases of Wuhan University, Transplant Center of Wuhan University, Hubei Key Laboratory of Medical Technology on Transplantation, Wuhan University; ${ }^{2}$ Department of Anesthesiology, Zhongnan Hospital of Wuhan University, Department of Anesthesiology, Wuhan University, Wuchang, Hubei 430071; ${ }^{3}$ The 3rd Xiangya Hospital of Central South University, Research Center of National Health Ministry on Transplantation Medicine Engineering and Technology, Changsha, Hunan 410013, P.R. China
\end{abstract}

Received April 7, 2015; Accepted July 16, 2015

DOI: $10.3892 /$ or.2016.4821

\begin{abstract}
Hepatocellular carcinoma (HCC) is a malignant tumor that has become a global health issue. The aim of the present study was to examine the role of transmembrane protein 9 (TMEM9) in cell progression, such as cell growth, cell cycle, cell metastasis of hepatoma cells, and to discuss the TMEM9 gene-encoding protein as a potential therapy target of hepatoma. RT-qPCR was performed to examine TMEM9 expression in tumor tissues and adjacent tissues of patients with liver cancer. siRNAs were used to interfere TMEM9 in HepG2 and 7721 cells. A CCK-8 assay was performed to evaluate cell growth at 24,48 and $72 \mathrm{~h}$. Cell cycle and apoptosis were analyzed using flow cytometry. Transwell assays were used to determine cell invasion, migration and adhesion. The results showed that TMEM9 was expressed abnormally in liver cancers. TMEM9 expression increased significantly in the 34 examined patients. TMEM9 knockdown inhibited proliferation in the HepG2 and 7721 cells. The flow cytometric analysis revealed that TMEM9 knockdown by RNA interference resulted in G1 arrest and induced apoptosis. Cell invasion, migration and adhesion ability were also decreased. Western blotting indicated that expression of the cell cycle-related proteins CDK1, EIF3H, RPL10L, S100A10, CCNB1 and CCNB2 was significantly decreased. In conclusion, TMEM9 plays an important role in the cell growth of hepatoma cells.
\end{abstract}

Correspondence to: Dr Yi Zhang or Qi-Fa Ye, Zhongnan Hospital of Wuhan University, Institute of Hepatobiliary Diseases of Wuhan University, Transplant Center of Wuhan University, Hubei Key Laboratory of Medical Technology on Transplantation, Donghu Road 169, Wuhan, Hubei 430071, P.R. China

E-mail: doctoryizhang@126.com

E-mail: ypf_china@163.com

Key words: TMEM9, hepatocellular carcinoma, cell proliferation, apoptosis, invasion

\section{Introduction}

The incidence of cancer is on the increase and one of the main causes of global mortality (1). Hepatocellular carcinoma (HCC) is a primary malignant tumor and the leading cause of cancer among cirrhotic patients, making it a global health issue $(2,3)$. HCC usually develops in the context of inflammation and organ injury (4). The pathogenic factors are varied. Hepatitis $B$ and $C$ viruses, and autoimmune hepatitis cause progressive liver disease and are major risk factors for the development of HCC (5-9). Due to the lack of effective therapies, such as standard chemotherapeutic agents, and the challenges experienced in early diagnosis, $\mathrm{HCC}$ patients have a poor prognosis (10). Therefore, new therapeutic targets may be identified from investigations into the molecular mechanism involved in liver cancer (11).

The membrane protein is a unique structure of protein that plays an important role in cell contact, signal transduction and enzyme activity. It has various functions and becomes the ideal drug target. CD151, as a 4 transmembrane protein gene, is associated with the invasion and metastasis of HCC (12). The transmembrane protein (TMEM) family sequence functions remain unknown only individual protein function has been reported. TMEM9 was characterized as a novel human transmembrane protein, belonging to a new protein family (13). The gene is localized to chromosome 1q41. To the best of our knowledge, the role of TMEM9 in HCC studies remains to be investigated.

In the present study, we investigated the function of the TMEM9 gene in HCC. The results suggest that this gene is closely associated with liver cancer. Thus, this may be a candidate gene for further study of molecular or therapeutic targets.

\section{Materials and methods}

Patients and tissue samples. Between 2008 and 2013, $70 \mathrm{HCC}$ patients presenting to the Zhongnan Hospital of Wuhan University (Hubei, China) were enrolled in the present study. All the patients had complete clinical and pathological follow-up data. Adjacent normal hepatocellular 
tissues were also collected as negative controls. These normal hepatocellular tissues were resected within at least $5 \mathrm{~cm}$ of the tumor margin when the patients underwent definitive surgery. Clinical fresh tissue samples were detected by qPCR. Approval for the study was provided by the independent Ethics Committee of the Zhongnan Hospital of Wuhan University. Informed and written consent was obtained from all the patients or their advisers according to the ethics committee guidelines.

Cell culture and transfection conditions. Human $97 \mathrm{H}$, 97L, HepG2, 7721, 7404 and HuH7 HCC cell lines were obtained from the American Type Culture Collection (ATCC; Manassas, VA, USA). The cells were grown in Dulbecco's modified Eagle's medium (DMEM) supplemented with $10 \%$ fetal bovine serum (FBS) and 1\% double antibiotics (penicillin/streptomycin) and maintained in a $37^{\circ} \mathrm{C}$ incubator with a $5 \% \mathrm{CO}_{2}$ humidified atmosphere. Transfections were performed using the Lipofectamine ${ }^{\mathrm{TM}} 2000$ reagent according to the manufacturer's instructions (Invitrogen Life Technologies, Carlsbad, CA, USA). After 48 h of transfection, the cells were used for cell proliferation assays, cell cycle analysis, and apoptosis, Matrigel invasion, migration and adhesion assays. Silencer negative control siRNA was used as a negative control.

RT-qPCR analysis. Cellular RNA was isolated using the TRIzol kit (Invitrogen Life Technologies). SYBR-Green RT-qPCR was performed to detect the mRNA expression. GADPH was used to normalize the RNA inputs. The primers used were: TMEM9 sense,5'-GGGCACATTTACAACCAG-3' and antisense, 5'-ATCAGGAAGGCCATGTAG-3'; GADPH sense, 5'-CACCCACTCCTCCACCTTTG-3' and antisense, 5'-CCACCACCCTGTTGCTGTAG-3'.

Cell proliferation assay. Viability of cells $72 \mathrm{~h}$ after transfection was assessed using the Cell Counting Kit-8 (CCK-8) (Qihai, Shanghai, China). Briefly, cells were seeded at a density of $3 \times 10^{4}$ in each 96-well plate and cultured for $0,24,48$ and $72 \mathrm{~h}$, respectively. CCK-8 reagent (100 $\mu \mathrm{l} /$ well) was added to each well and incubated for $1 \mathrm{~h}$ at $37^{\circ} \mathrm{C}$. The optical density (OD) values were determined at $450 \mathrm{~nm}$ using a microplate reader. Three different experiments were performed for each experimental condition.

Flow cytomery. The cell cycle was assessed by flow cytometric analysis at different time points using a propidium iodide (PI) cell cycle detection kit (Beyotime, Shanghai, China). The cells were collected, treated and stained with PI according to the manufacturer's instructions. The cell cycle was detected using a flow cytometer (BD Biosciences, Heidelberg, Germany).

Apoptotic cells were visualized using an Annexin V-FITC/PI kit (BD Biosciences, San Jose, CA, USA). The apoptosis of HCC-transfected cells were determined by flow cytometric (FCM) analysis using a FACSCalibur.

Cell invasion and migration. After transfection, the cells were detached and washed twice in PBS. Then, $1 \times 10^{5}$ cells $/ \mathrm{ml}$ were seeded in the upper chamber of a Transwell insert
(8- $\mu \mathrm{m}$ pore size) coated (invasion) or not coated (migration) with $80 \mu \mathrm{l}$ Matrigel (BD Biosciences). The lower chamber was filled with $0.75 \mathrm{ml}$ of DMEM. After a 48-h (invasion) or 24-h (migration) incubation period, the non-migrated cells in the upper chamber were scraped away, and adherent cells were stained with formaldehyde solution. Any cells on the underside were counted and photographed under $\mathrm{x} 200$ microscope fields.

Cell adhesion. To determine the adhesion cells, 12-well plates were used. Cell suspension $\left(1 \times 10^{5}\right.$ cells $\left./ \mathrm{ml}\right)$ was added to the well and incubated for $1 \mathrm{~h}$ at $37^{\circ} \mathrm{C}$. Adherent cells were fixed with $4 \%$ methanol and stained with crystal violet for $20 \mathrm{~min}$. The number of adherent cells were photographed and counted from three random selected x200 fields of microscope.

Channel protein expression detection. To detect the role of TMEM9 in liver cancer cells, we selected the proteins CCNB1, CCNB2, CDK1, PRL10A, S100A10 and EIF3H to detect the protein expression using western blotting. Protein lysates were prepared. Equal amounts of samples were resolved by SDS-PAGE and transferred to nitrocellulose membranes. The membranes were then blocked with $5 \%$ low-fat milk for $1 \mathrm{~h}$ or overnight at $4^{\circ} \mathrm{C}$; incubated with CCNB1, CCNB2, CDK1, PRL10A, S100A10 and EIF3H with primary antibodies for $2 \mathrm{~h}$, followed by secondary antibodies for $1 \mathrm{~h}$ at room temperature; and analyzed. GADPH protein levels were determined as a loading control.

Statistical analysis. Statistical significances were determined using the GraphPad Prism v5.0 software (GraphPad Software, La Jolla, CA, USA). Kaplan-Meier analysis was used to determine that the overall survival time between low and high expression of HCC. Data are presented as the mean \pm SD of at least three independent replicates. Differences were considered significant when $\mathrm{P}<0.05$ or $\mathrm{P}<0.01$.

\section{Results}

TMEM9 is highly expressed in HCC with poor patient survival. To investigate the expression of TMEM9, we used RT-qPCR to investigate in the HCC tissues of 30 patients. The results showed a higher level of TMEM9 expression (Fig. 1A). Then we investigated the correlation between TMEM9 expression and prognosis of the patients with HCC. As shown in Fig. 1B, Kaplan-Meier analysis showed that the overall survival time of lower-TMEM9-expressing patients was notably higher than that of higher-TMEM9-expressing patients. The expression levels of TMEM9 in the six HCC cells were also evaluated by qPCR and western blotting (Fig. 1C and D). The HepG2 and 7721 cell lines had a higher TMEM9 mRMA and protein expression.

Knockdown of TMEM9 inhibits cell proliferation and induces apoptosis. To assess the potential effects of RNAi silencing TMEM9 on proliferation, CCK-8 analysis was performed $72 \mathrm{~h}$ after transfection. The proliferative ability of HepG2 and 7721 cells was significantly inhibited at 24,48 and 72 h (Fig. 2).

Moreover, we investigated the effects of TMEM9 on cell cycle and apoptosis in HCC. The flow cytometric analysis 

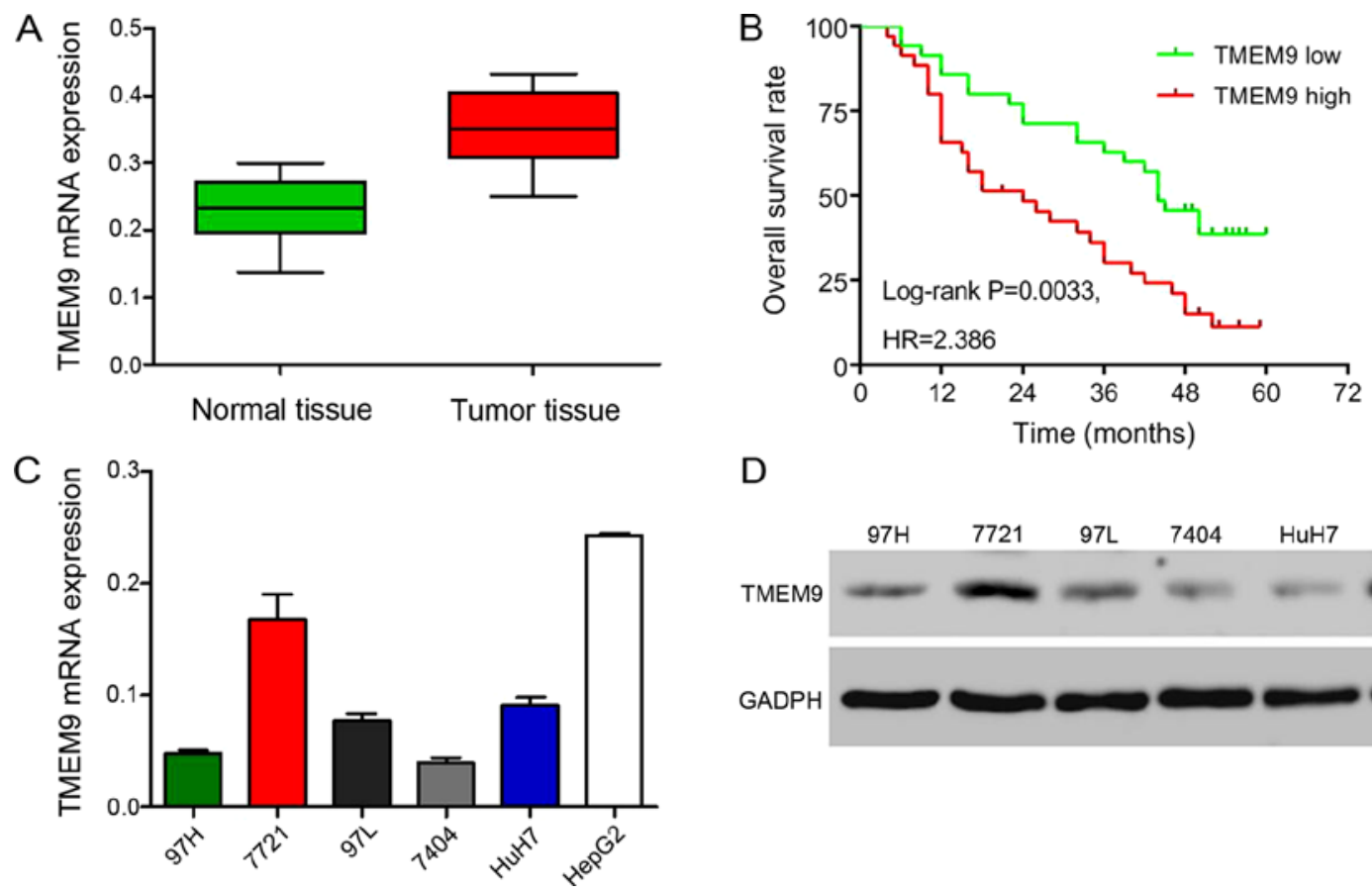

D

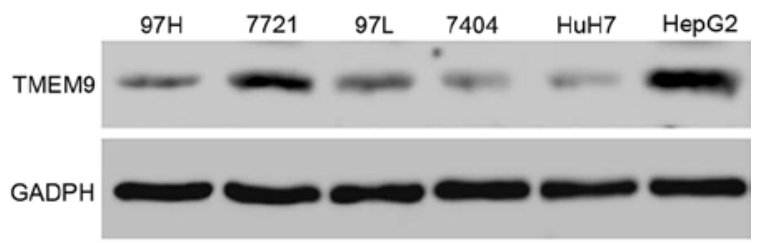

Figure 1. High expression of TMEM9 is associated with the patient survival rate. (A) The mRNA expression level of TMEM9 was detected in tumor and adjacent tissues. (B) High expression of TMEM9 had a slightly higher survival rate. (C and D) The expression of TMEM9 was analyzed by RT-qPCR and western blotting in the six HCC cell lines. TMEM9, transmembrane protein 9; HCC, hepatocellular carcinoma.

$\mathbf{A}$

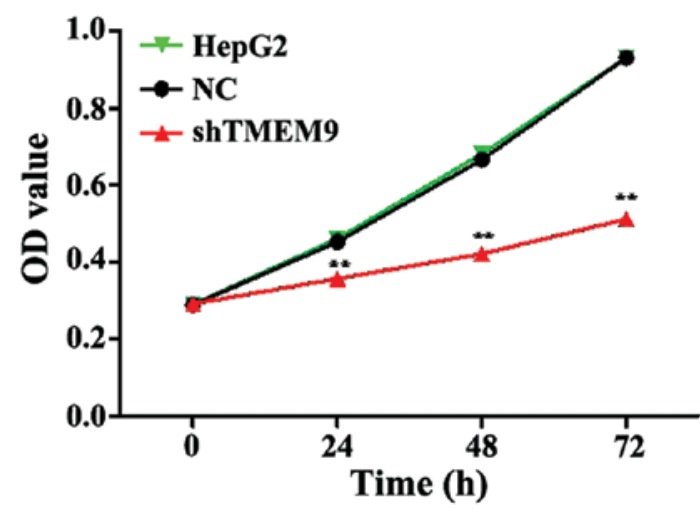

B

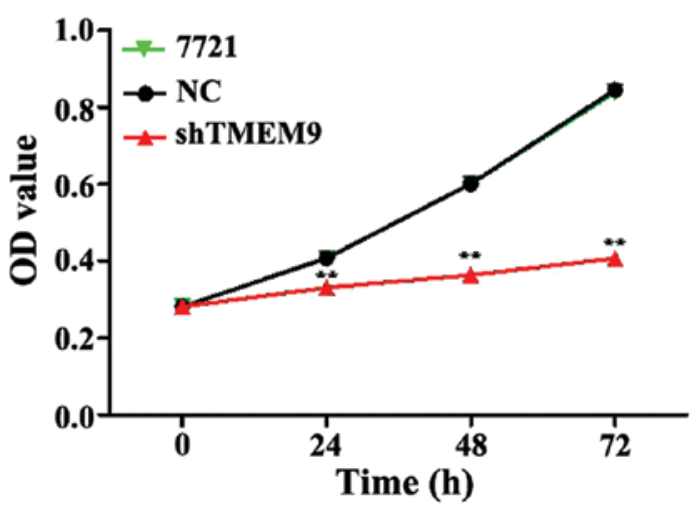

Figure 2. Effects of TMEM9 on cell proliferation of HepG2 and 7721 cells. (A) Cell proliferation was detected at 0, 24, 48 and $72 \mathrm{~h}$ in HepG2, NC and sh-TMEM9 cells. (B) Cell proliferation was detected in 7721, NC and sh-TMEM9 cells. NC, negative control; TMEM9, transmembrane protein 9.

revealed that the population of G0/G1 phase was significantly increased but that of $\mathrm{S}$ and $\mathrm{G} 2 / \mathrm{M}$ phase was decreased in HepG2 and 7721 cells, when compared with the negative control (NC) $(\mathrm{P}<0.01)$ (Fig. 3).

In addition, we assessed the apoptotic function of TMEM9 in HepG2 and 7721 cells using the Annexin V-FITC/PI staining assay. As shown in Fig. 4, the results showed that knockdown of TMEM9 in HCC cells markedly induced the cell apoptotic rate compared with $\mathrm{NC}(\mathrm{P}<0.01)$.

Knockdown of TMEM9 decreases metastasis of HCC cells. Cell metastasis plays an important role in cancer progression. We determined whether TMEM9 regulated metastasis of HCC cells. Cell invasion, migration and adhesion assays were then used to detect the metastatic capacity. As shown in
Fig. 5, the cell invasion ability was reduced when compared with $\mathrm{NC}(\mathrm{P}<0.01)$. The migration and adhesion cells were also decreased $(\mathrm{P}<0.01)$ (Figs. 6 and 7$)$.

Knockdown of TMEM9 decreases protein expression in HCC. Signaling pathways are often activated in tumor cells. We assessed the protein expression using western blotting. The results showed that the protein expression of CDK1, EIF3H, RPL10L, S100-A10, CCNB1 and CCNB2 was decreased compared to the control group $(\mathrm{P}<0.01)$ (Fig. 8).

\section{Discussion}

$\mathrm{HCC}$ is one of the most common types of cancer worldwide. Of an estimated 700,000 cancer-associated mortalities that 
A
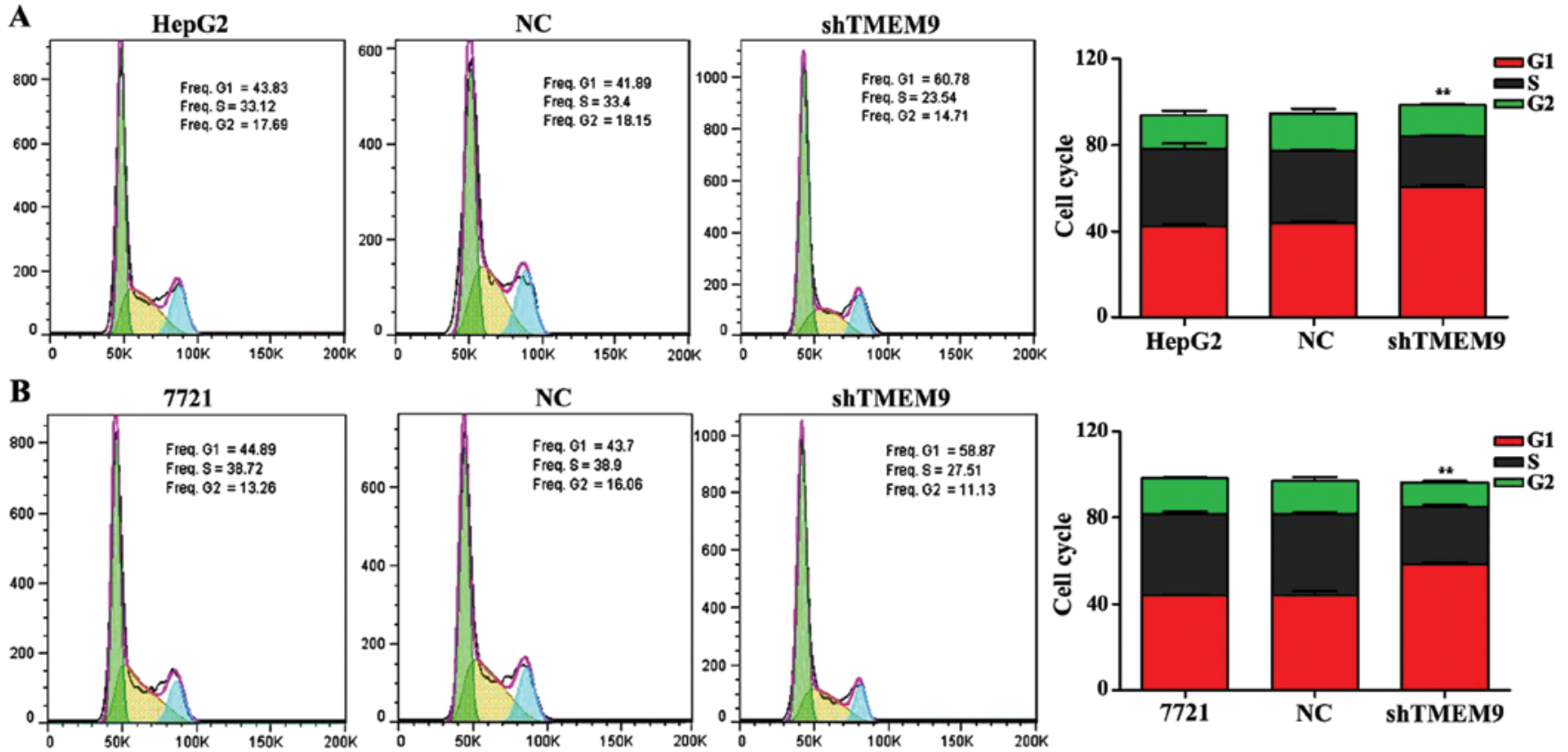

Figure 3. Effects of TMEM9 on cell cycle of HCC cells. (A) After TMEM9-siTNA transfection for $48 \mathrm{~h}$, cell cycle distribution of HepG2 cells was identified by flow cytometry. (B) Cell cycle distribution of 7721, NC and shTMEM9 were detected. Data are based on at least 3 independent experiments and shown as mean $\pm \mathrm{SD} .{ }^{* *} \mathrm{P}<0.01$, compared with the negative control. NC, negative control; TMEM9, transmembrane protein 9 .

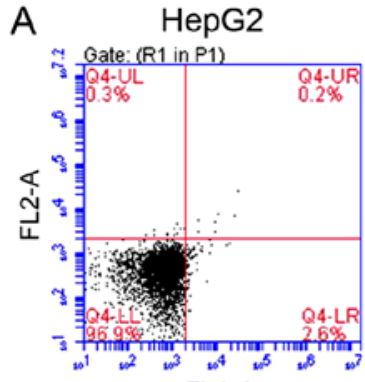

FL1-A

B

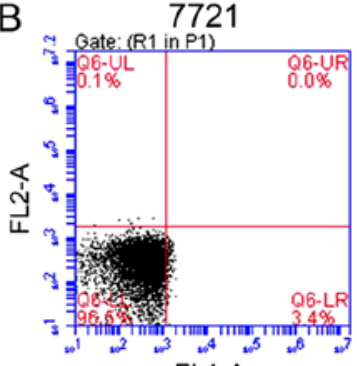

FL1-A

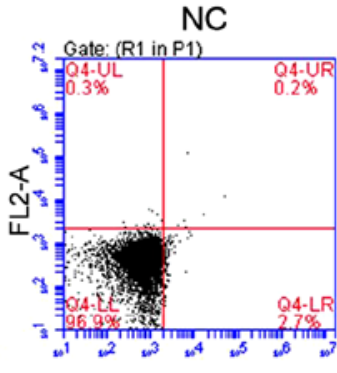

FL1-A

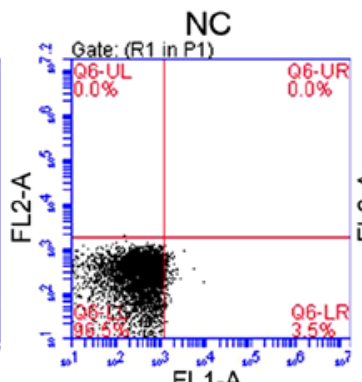

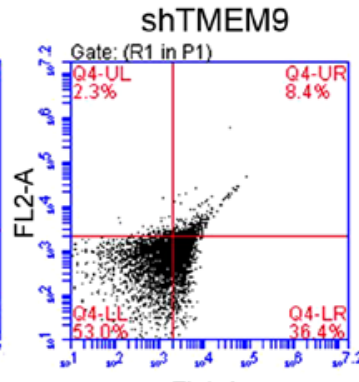

FL1-A

ShTMEM9

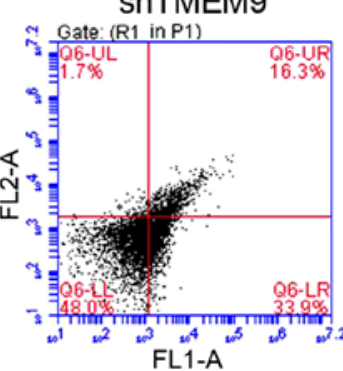

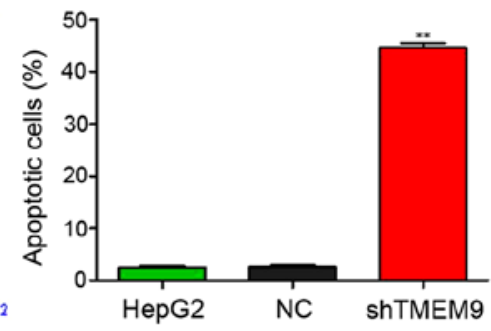

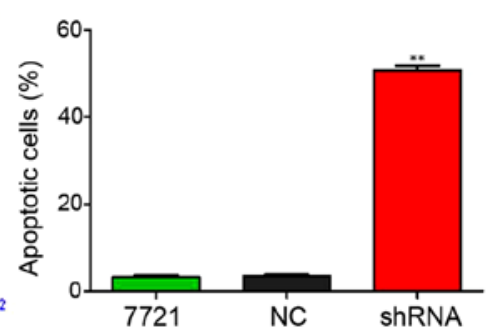

Figure 4. Effects of TMEM9 on cell apoptosis of HCC cells. (A) After HepG2 cells were transfected for $48 \mathrm{~h}$, the apoptotic rates of HepG2 cells were analyzed using flow cytometry. (B) The apoptotic rates of $7721, \mathrm{NC}$ and shTMEM9 were detected. ${ }^{* *} \mathrm{P}<0.01$, compared with the negative control.TMEM9, transmembrane protein 9; HCC, hepatocellular carcinoma.

arising in $2008,50 \%$ occurred in China $(2,14)$. The 5 -year survival rate remains at $<40 \%$ following surgery (15). HCC cause serious damage to human health; thus, investigation of its development mechanism and identification of effective measures of prevention, diagnosis and treatment of HCC is crucial. In the present study, we investigated the biological function of TMEM9 in HCC cells (16). The clinical data show that TMEM9 was highly expressed in HCC patients. Moreover, TMEM9 expression was associated with the patient survival rate. The in vitro experiments showed that knockdown of TMEM9 in HCC HepG2 and 7721 cancer cells inhibited cell growth and metastasis, and promoted cell apoptosis. Thus, TMEM9 serves as a potential target for the treatment of HCC.

In order to elucidate the possible mechanism involved, we identified the related protein expression. CDK1 is a highly conserved protein and a key player in the cell cycle regulation (17). Eukaryotic translation initiation factors (EIFs) are involved in the protein translation initiation process, and EIF2, 


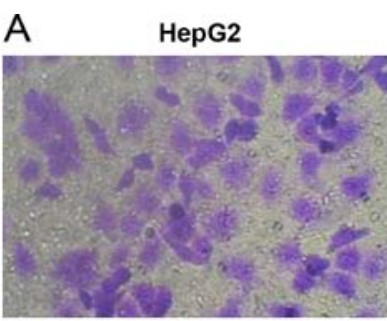

B

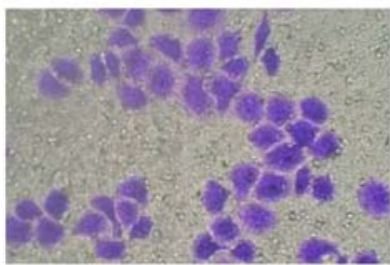

C

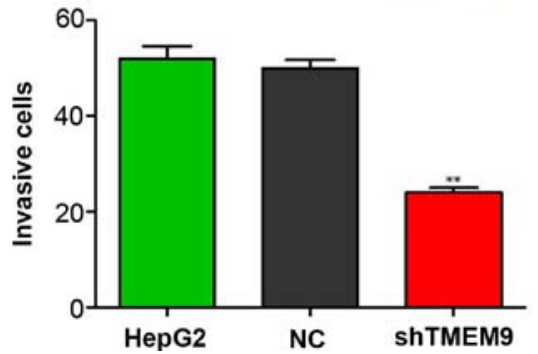

NC

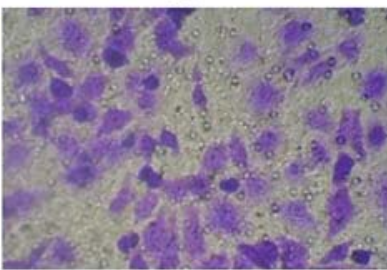

NC
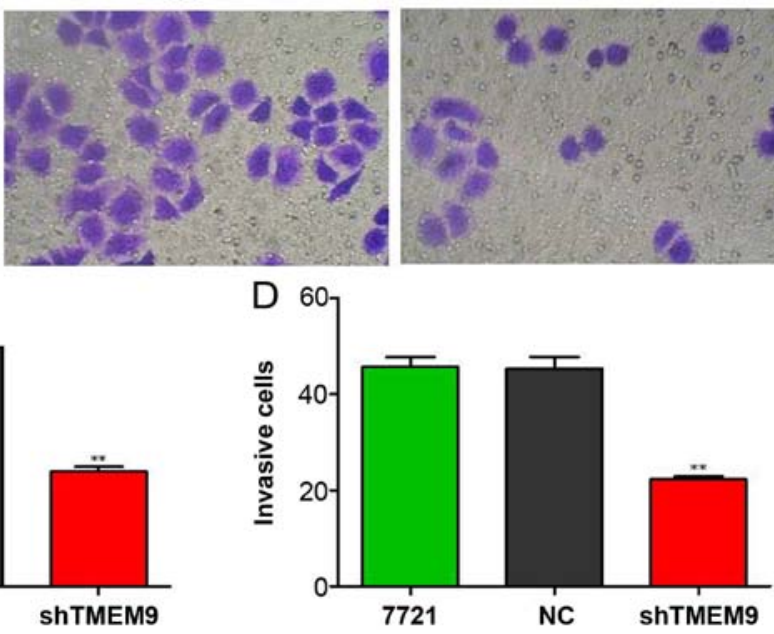

ShTMEM9

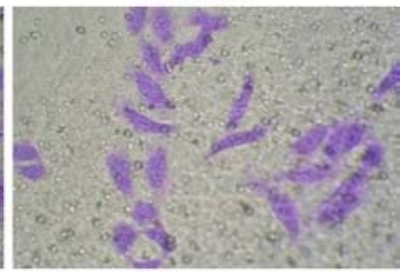

ShTMEM9

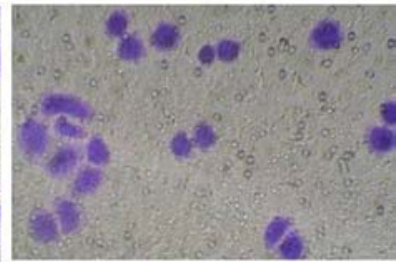

Figure 5. TMEM9 knockdown decreased invasion capacity of HCC cells in vivo. (A and B) Images of HepG2 and 7721 invasion cells were captured in $48 \mathrm{~h}$ after seeding. (C and D) Invasion assays showed that invasion cells were decreased than those in the negative group. ${ }^{* *} \mathrm{P}<0.01$, compared with the negative control. TMEM9, transmembrane protein 9; HCC, hepatocellular carcinoma.

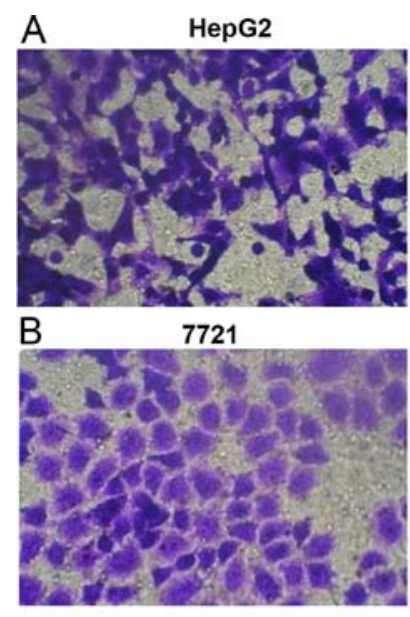

\section{$\mathrm{C}$}

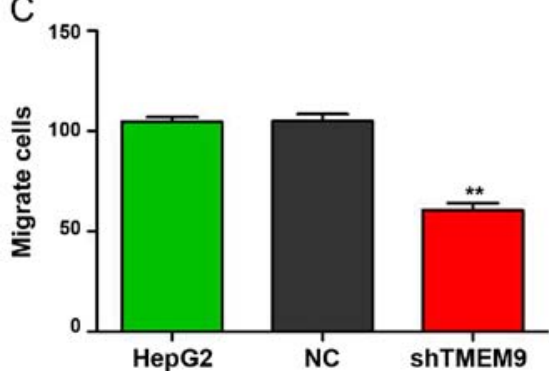

NC
NC
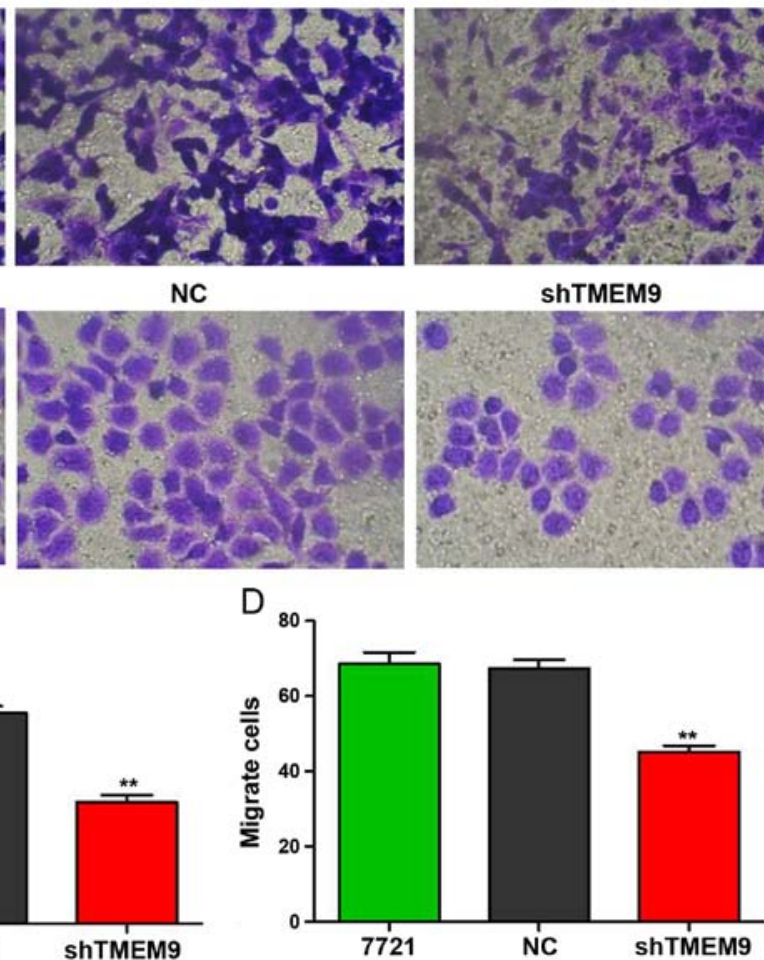

ShTMEM9

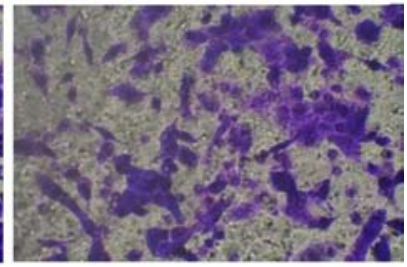

ShTMEM9

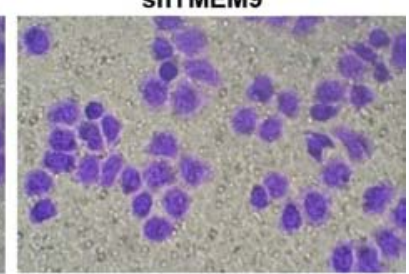

ShTMEM9

Figure 6. Knockdown of TMEM9 decreases cell migration in HCC cells. (A and B) The images of HepG2 and 7721 migrated cells were captured in 48 h after seeding. (C and D) Migrations of HCC cells were assayed using the 24-Transwell system. Data are one of three similar experiments. ${ }^{* *} \mathrm{P}<0.01$, when compared with the negative controls. TMEM9, transmembrane protein 9; HCC, hepatocellular carcinoma.

EIF3, EIF4 and EIF5 have been previously investigated (18). EIF3H is an important subunit of the EIF3 family. The EIF3H expression level is closely associated with a variety of tumors, and is overexpressed in numerous malignant tumors $(19,20)$. 

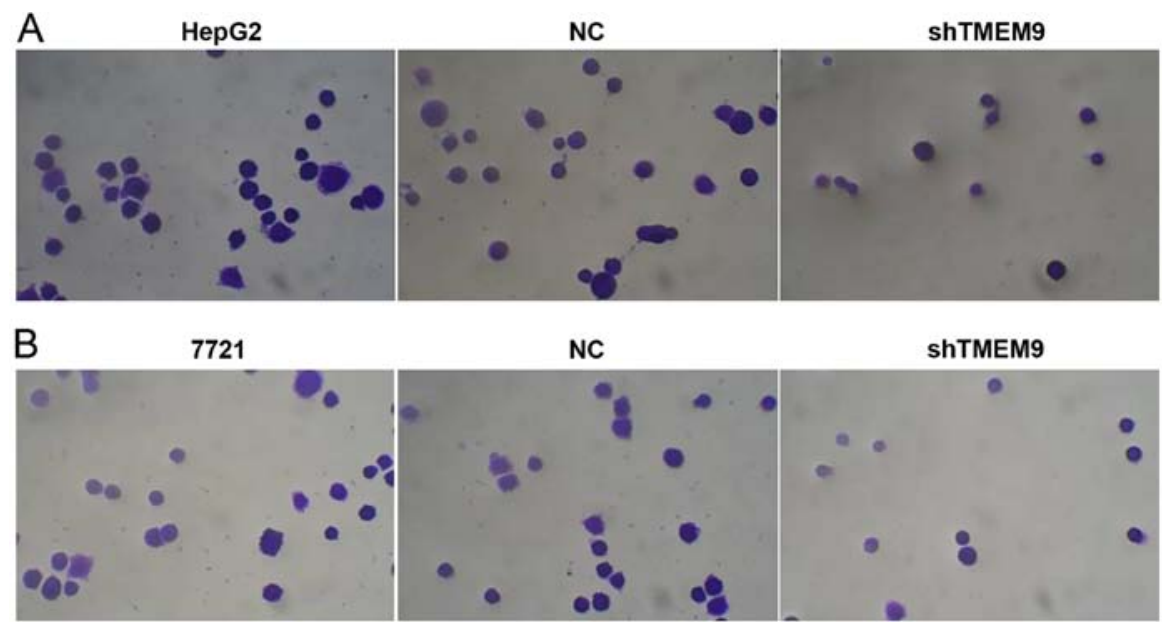

NC ShTMEM9
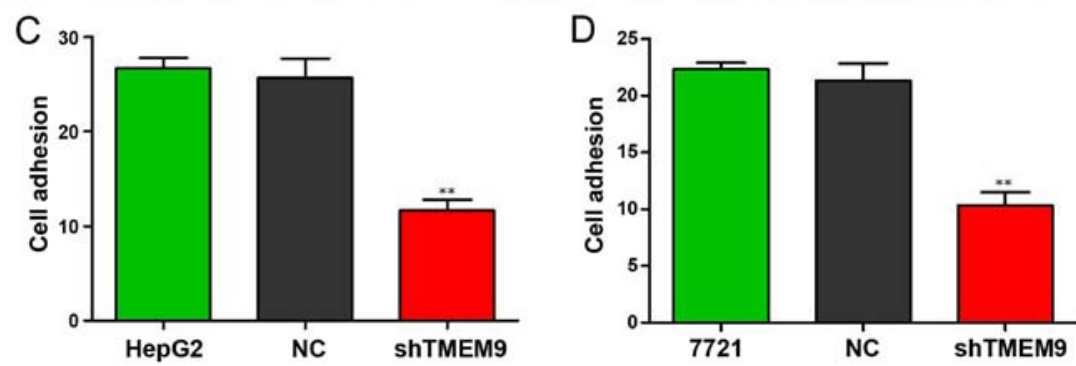

Figure 7. Knockdown of TMEM9 decreased cell adhesion in HCC cells. (A and B) The images of HepG2 and 7721 migrate cells were captured in $48 \mathrm{~h}$ after seeding. (C and D) The adhesion of HCC cells were identified after transfection. ${ }^{* *} \mathrm{P}<0.01$, when compared with the negative controls. TMEM9, transmembrane protein 9; HCC, hepatocellular carcinoma.
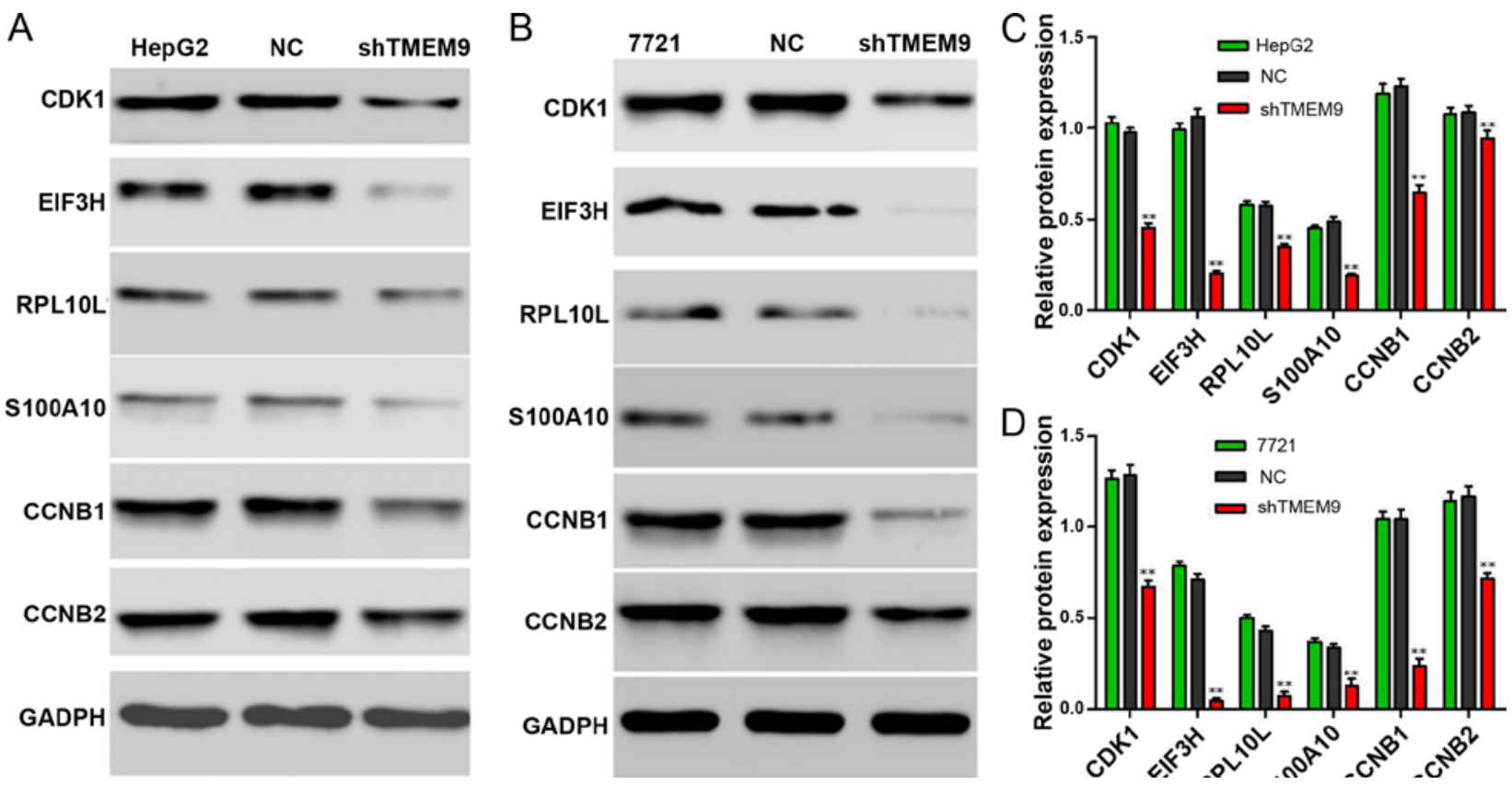

Figure 8. Western blotting results of TMEM9 influenced proteins. (A and B) After $48 \mathrm{~h}$ of TMEM9 siRNA treatment, the protein expression of CDK1, EIF3H, RPL10L, S100A10, CCNB1 and CCNB2 in HepG2 and 7721 cells were detected by western blotting, GADPH was detected as the control of sample loading. (C and D) Western blotting data are analyzed to identify the protein levels. ${ }^{* *} \mathrm{P}<0.01$ compared with the NC cells.

Ribosomal protein L 10-like (RPL10L), a protein-coding gene, has a structural constituent of ribosome. Furthermore, S100A10, CCNB1 and CCNB2 are involved in mitosis and the regulation of cell cycle progression (21-23). Our results show that the cell cycle-related protein expressions were significantly decreased when compared with NC.
In summary, to the best of our knowledge, the present study provides evidence for the first time that TMEM9 is crucial in the cell proliferation, apoptosis and metastasis of HCC cells. Additionally, TMEM9 regulates these biological processes by regulating cell cycle-related proteins. As TMEM9 expression level is associated with the patient survival rate, inhibition 
of TMEM9 in tumor tissues provides a therapeutic strategy. However, additional investigations should be conducted to validate its therapeutic function in the future.

\section{Acknowledgements}

The present study was supported by the Natural Science Fund of Hubei Province (no. 2012FFA044), the Health Department Found of Hubei Province (no. JX6B18), and the Public Service Platform Construction Projects of Wuhan Technology Bureau (no. 2013060705010326).

\section{References}

1. Mathers C, Fat DM and Boerma JT: The Global Burden of Disease: 2004 Update. World Health Organization, 2008.

2. Jemal A, Bray F, Center MM, Ferlay J, Ward E and Forman D: Global cancer statistics. CA Cancer J Clin 61: 69-90, 2011.

3. Bosch FX, Ribes J, Díaz M and Cléries R: Primary liver cancer: Worldwide incidence and trends. Gastroenterology 127 (Suppl 1): S5-S16, 2004.

4. Villanueva A, Newell P, Chiang DY, Friedman SL and Llovet JM Genomics and signaling pathways in hepatocellular carcinoma Semin Liver Dis 27: 55-76, 2007.

5. Yuen MF, Tanaka Y, Fong DY-T, Fung J, Wong DK, Yuen JC, But DY, Chan AO, Wong BC, Mizokami M, et al: Independent risk factors and predictive score for the development of hepatocellular carcinoma in chronic hepatitis B. J Hepatol 50: 80-88, 2009.

6. Yang HI, Sherman M, Su J, Chen PJ, Liaw YF, Iloeje UH and Chen CJ: Nomograms for risk of hepatocellular carcinoma in patients with chronic hepatitis B virus infection. J Clin Oncol 28: 2437-2444, 2010.

7. Lok AS, Seeff LB, Morgan TR, di Bisceglie AM, Sterling RK, Curto TM, Everson GT, Lindsay KL, Lee WM, Bonkovsky HL, et al; HALT-C Trial Group: Incidence of hepatocellular carcinoma and associated risk factors in hepatitis C-related advanced liver disease. Gastroenterology 136: 138-148, 2009.

8. Yeoman AD, Al-Chalabi T, Karani JB, Quaglia A, Devlin J, Mieli-Vergani G, Bomford A, O'Grady JG, Harrison PM and Heneghan MA: Evaluation of risk factors in the development of hepatocellular carcinoma in autoimmune hepatitis: Implications for follow-up and screening. Hepatology 48: 863-870, 2008.

9. Wang X, Wang N, Cheung F, Lao L, Li C and Feng Y: Chinese medicines for prevention and treatment of human hepatocellular carcinoma: Current progress on pharmacological actions and mechanisms. J Integr Med 13: 142-164, 2015.
10. Lopez PM, Villanueva A and Llovet JM: Systematic review: Evidence-based management of hepatocellular carcinoma - an updated analysis of randomized controlled trials. Aliment Pharmacol Ther 23: 1535-1547, 2006.

11. Villanueva A, Toffanin S and Llovet JM: Linking molecular classification of hepatocellular carcinoma and personalized medicine: Preliminary steps. Curr Opin Oncol 20: 444-453, 2008.

12. Ke AW, Shi GM, Zhou J, Huang XY, Shi YH, Ding ZB, Wang XY, Devbhandari RP and Fan J: CD151 amplifies signaling by integrin $\alpha 6 \beta 1$ to PI3K and induces the epithelial-mesenchymal transition in HCC Cells. Gastroenterology 140: 1629-1641.e15, 2011.

13. Kveine M, Tenstad E, Døsen G, Funderud S and Rian E: Characterization of the novel human transmembrane protein 9 (TMEM9) that localizes to lysosomes and late endosomes. Biochem Biophys Res Commun 297: 912-917, 2002.

14. Ferlay J, Shin HR, Bray F, Forman D, Mathers C and Parkin DM: Estimates of worldwide burden of cancer in 2008: GLOBOCAN 2008. Int J Cancer 127: 2893-2917, 2010.

15. Fang F, Yang L, Tao Y and Qin W: FBI-1 promotes cell proliferation and enhances resistance to chemotherapy of hepatocellular carcinoma in vitro and in vivo. Cancer 118: 134-146, 2012.

16. Zhai XF, Chen Z, Li B, Shen F, Fan J, Zhou WP, Yang YK, Xu J, Qin X, Li LQ and Ling CQ: Traditional herbal medicine in preventing recurrence after resection of small hepatocellular carcinoma: a multicenter randomized controlled trial. J Integr Med 11: 90-100, 2013

17. Morgan DO: The Cell Cycle: Principles of Control. New Science Press, 2007.

18. Spilka R, Ernst C, Mehta AK and Haybaeck J: Eukaryotic translation initiation factors in cancer development and progression. Cancer Lett 340: 9-21, 2013.

19. Okamoto H, Yasui K, Zhao C, Arii S and Inazawa J: PTK2 and EIF3S3 genes may be amplification targets at 8q23-q24 and are associated with large hepatocellular carcinomas. Hepatology 38 : 1242-1249, 2003.

20. Cappuzzo F, Varella-Garcia M, Rossi E, Gajapathy S, Valente M, Drabkin H and Gemmill R: MYC and EIF3H coamplification significantly improve response and survival of non-small cell lung cancer patients (NSCLC) treated with gefitinib. J Thorac Oncol 4: 472-478, 2009.

21. Jackman M, Firth M and Pines J: Human cyclins B1 and B2 are localized to strikingly different structures: B1 to microtubules, B2 primarily to the Golgi apparatus. EMBO J 14: 1646-1654, 1995.

22. Porter LA, Singh G and Lee JM: Abundance of cyclin B1 regulates $\gamma$-radiation-induced apoptosis. Blood 95: 2645-2650, 2000.

23. Rescher U and Gerke V: S100A10/p11: Family, friends and functions. Pflugers Arch 455: 575-582, 2008. 